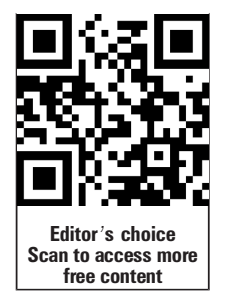

${ }^{1}$ Robert Wood Johnson Clinical Scholar, Perelman School of Medicine at the University of Pennsylvania, Philadelphia, Pennsylvania, USA ${ }^{2}$ VA Center for Health Equity Research and Promotion, Department of Family Medicine and Community Health, Perelman School of Medicine at the University of Pennsylvania, Philadelphia, Pennsylvania, USA ${ }^{3}$ Department of Biostatistics and Epidemiology, Perelman School of Medicine, University of Pennsylvania, Philadelphia, Pennsylvania, USA

\section{Correspondence to}

Dr Eugenia C Garvin, Robert Wood Johnson Clinical Scholars, Perelman School of Medicine at the University of Pennsylvania, 13th Fl Blockley Hall, 423 Gaurdian Dr. Philadelphia, PA 19104, USA; eugenia.garvin@uphs.upenn. edu

Accepted 27 June 2012 Published Online First 7 August 2012

\title{
Greening vacant lots to reduce violent crime: a randomised controlled trial
}

\author{
Eugenia C Garvin, ${ }^{1}$ Carolyn C Cannuscio,, ${ }^{2}$ Charles C Branas ${ }^{3}$
}

\section{ABSTRACT}

Background Vacant lots are often overgrown with unwanted vegetation and filled with trash, making them attractive places to hide illegal guns, conduct illegal activities such as drug sales and prostitution, and engage in violent crime. There is some evidence that greening vacant lots is associated with reductions in violent crime. Methods We performed a randomised controlled trial of vacant lot greening to test the impact of this intervention on police reported crime and residents' perceptions of safety and disorder. Greening consisted of cleaning the lots, planting grass and trees, and building a wooden fence around the perimeter. We randomly allocated two vacant lot clusters to the greening intervention or to the control status (no intervention). Administrative data were used to determine crime rates, and local resident interviews at baseline $(n=29)$ and at follow-up $(n=21)$ were used to assess perceptions of safety and disorder. Results Unadjusted difference-in-differences estimates showed a non-significant decrease in the number of total crimes and gun assaults around greened vacant lots compared with control. People around the intervention vacant lots reported feeling significantly safer after greening compared with those living around control vacant lots $(p<0.01)$.

Conclusions In this study, greening was associated with reductions in certain gun crimes and improvements in residents' perceptions of safety. A larger randomised controlled trial is needed to further investigate the link between vacant lot greening and violence reduction.

\section{INTRODUCTION}

Community violence affects the physical and mental health of individuals, as well as the social health of neighbourhoods, often in geographic 'hot spots'. ${ }^{1-6}$ Preventing violence requires understanding the people living in a hot spot, but also understanding how the physical environment in a hot spot may promote or retard violence. ${ }^{7}$ Interventions that modify the physical environment represent an important opportunity for violence prevention, as they can potentially impact more people for longer periods of time and cost less money than individual or lifestyle interventions. $^{8-10}$

Vacant lots and abandoned buildings are prominent and highly visible signs of a disordered physical environment, and have been associated with violence, fear and further disorder. ${ }^{11-18}$ Vacant lots and abandoned buildings pose significant problems for many former manufacturing cities. ${ }^{19} 20$ Philadelphia, for example, has an inventory of over 40000 vacant lots and the percentage of land that is vacant in other major US cities ranges from about $10 \%$ in New York City to $40 \%$ or more in Fort
Worth, Phoenix and Tallahassee. ${ }^{21} 22$ Vacant lots are often overgrown with unwanted vegetation and filled with trash, making them potentially attractive places for activities such as prostitution, illegal drug sales and use, and illegal gun storage. ${ }^{14} 23-25$

Few studies have examined vacant lot interventions to reduce violence. One study has considered the impact of greening thousands of vacant lots using a quasi-experimental difference-in-differences design. ${ }^{24}$ This study documented a significant before-after reduction in gun assaults around vacant lots that were greened compared with lots that were not greened. Proposed explanations for this observed reduction in violence include the elimination of access to a specific, physical promoter of violence, namely, a place to hide illegal guns. Additionally, the greening of vacant lots may enhance community pride and provide sites for social gathering and interaction, thereby increasing informal policing, collective efficacy and social connectivity. ${ }^{24} 26-29$

Randomised controlled trials of vacant lot greening are now needed to provide the best evidence to urban planners and city officials interested in greening as a strategy to prevent violence. The current study represents the first randomised controlled trial of vacant lot greening. The aim of this study was to gather preliminary evidence for the impact of vacant lot greening on violencerelated outcomes, including police reported crime and perceptions of safety and disorder.

\section{METHODS}

\section{Vacant lot selection and greening}

Vacant lot greening was the randomly assigned intervention in this trial. The Pennsylvania Horticulture Society (PHS) performed the greening using a standard, reproducible protocol that consisted of: (a) removing debris, (b) grading the land and adding topsoil, (c) planting grass and trees, (d) building a low, post-and-rail wooden fence with entry openings around the perimeter and (e) maintenance every 2 weeks. ${ }^{30}$ The PHS has greened over 7.8 million square feet of vacant land in the City of Philadelphia through its Vacant Land Management Program. To bolster the effect of greening, the PHS typically greens vacant lots in neighbouring, but not necessarily contiguous, clusters of approximately 5000 square feet. Figure 1 depicts a vacant lot greened by the PHS (for purposes of confidentiality, this is not a study vacant lot).

A master database of 54132 vacant lots in Philadelphia in 2008 was used to randomly select vacant lots for the intervention and control sites. The database was compiled from the Philadelphia 
Figure 1 Before and after vacant lot greening by the Pennsylvania Horticulture Society.

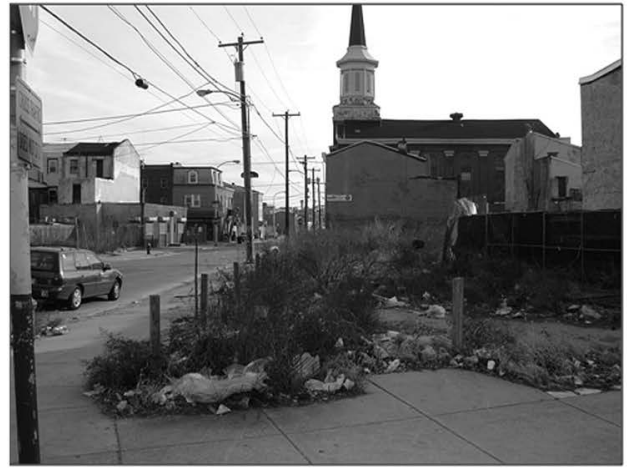

Before greening

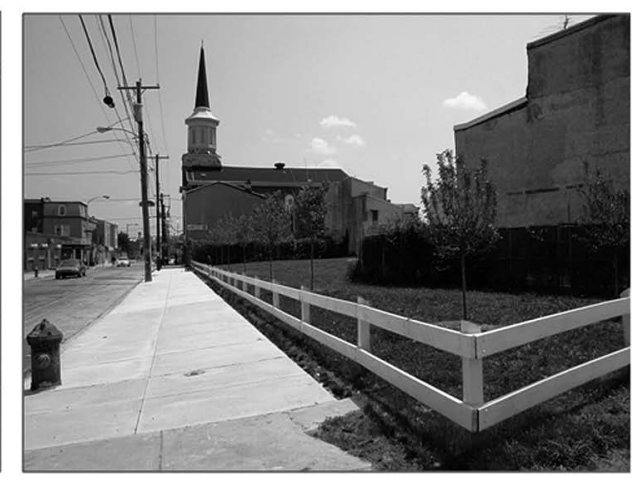

After greening
Bureau of Revision of Taxes, the Philadelphia Department of Licenses and Inspections, and the US Postal Service records, and was maintained by the Cartographic Modeling Lab at the University of Pennsylvania. To be selected for randomisation, vacant lots had to meet the following eligibility criteria: (1) location in one designated section of the city (Philadelphia has a total of five geographic sections), (2) at least one city code violation, (3) no prior greening efforts by the PHS or the City of Philadelphia and (4) at least 4500 square feet of vacant lot space within a surrounding 660 square feet buffer. After exclusion criteria were applied to the master database, 2814 vacant lots remained. These vacant lots were randomly sorted and the top 50 served as index vacant lots. Index lots were grouped with other vacant lots in closest proximity to create 50 clusters each totalling 4500-5500 square feet of vacant lot space.

Each vacant lot cluster was viewed with the PHS to determine which were appropriate to send to the city for authorisation for greening. The most common reason for not sending a cluster for authorisation was lack of a current city code violation. Many did not yet have significant vegetation growth due to the season, early spring, in which we conducted the lot selection. The index lot (and its corresponding cluster) that was the highest on the randomly sorted list and that was approved by the City of Philadelphia was designated the intervention site, and the next highest was designated the control site. The PHS did not influence the randomisation process and were not involved in data collection. The greening intervention took place in May 2011.

\section{Participant selection}

People living in homes approximately two blocks surrounding the randomly selected vacant lots were eligible to participate in the study. Participants had to be 18-65-years-old and able to walk unassisted and without difficulty. One resident per home was eligible. Community-based interviewers first placed 'door knockers'-pamphlets with the study description and phone number-on all eligible homes. The interviewers walked doorto-door the following week to recruit participants.

In order to keep participants blinded to the effect of the greening intervention, participants were told that the study was about perceptions of safety and violence in their neighbourhood. Participants received $\$ 20$ to complete a $1 \mathrm{~h}$ baseline interview and $\$ 30$ to complete a $1 \mathrm{~h}$ follow-up interview 2-3 months after the greening intervention. At the intervention site, 14 residents completed the baseline interview and 10 completed the followup interview. At the control site, 15 residents completed the baseline interview and 11 completed the follow-up interview. The trial was approved by the Institutional Review Board at the University of Pennsylvania.

\section{Measures and statistical analysis}

At both baseline and follow-up, the study protocol included an inhome survey and qualitative interview followed by a walking interview around the neighbourhood that brought participants past the study vacant lots. The results of the qualitative and walking interview will be analysed in separate manuscripts. All interviews took place between April 2011 and August 2011. Study data were collected and managed using REDCap electronic data capture tools hosted at the University of Pennsylvania. ${ }^{31}$ All analyses were done using Stata V.11 and ArcGIS V.10 (Redlands, California, USA).

\section{Police reported crime}

We obtained the dates and longitude-latitude coordinates of several types of crimes from the Philadelphia Police Department for 3.5 months before and 3.5 months after the greening intervention. Crimes included aggravated assaults with and without guns, robberies with and without guns, narcotics sales and possession, burglaries, thefts, vandalism, disorderly conduct, public drunkenness, and illegal dumping. We were unable to analyse $3.3 \%$ of the crimes obtained from the police due to the inability to geocode the original data.

We created a half-mile buffer around the two vacant lot study sites and measured the number of crimes within the buffer both before and after the intervention. We used an unadjusted difference-in-differences approach to compare crimes rates from the intervention and control sites before and after greening. We statistically compared the proportion of total crimes across sites before and after the greening that took place at the intervention site. We were unable to run an adjusted regression model for crime due to the low number of two vacant lot study sites.

\section{Perceptions of disorder}

Following informed consent, the study team collected demographics and a previously validated self-reported neighbourhood disorder scale. ${ }^{16}$ The scale uses a four point Likert response and measures physical and social disorder and order with 15 questions such as 'There is a lot of graffiti in my neighborhood', 'My neighborhood is clean', 'I'm always having trouble with my neighbors' and 'My neighborhood is safe.' The disorder score was calculated by adding up each of the 15 scale items for a maximum score of 60 and minimum score of 15. A higher score indicates increasing perceived disorder. Items indicating physical or social order were reverse coded.

We used a randomised trial difference-in-differences approach to evaluate the impact of the greening intervention on perceptions of disorder and its subcomponents for 21 participants who completed baseline and follow-up interviews. ${ }^{32}$ We created linear regression models for each outcome of interest, $Y_{i}$, including the 
total disorder scale and each item of the scale. The focal independent variable in the linear regression model was the difference-in-differences term, $P_{i} \times R_{i}$, defined as the interaction between a pregreening-postgreening difference per vacant lot, $P_{i}$, where pregreening period was 0 and postgreening period was 1 , and an intervention-control difference, $R_{i}$, where control lots were 0 and greened lots were 1 . A series of $s$ independent covariates, including gender, age, race and income, as well as the error term, $\varepsilon_{\mathrm{i}}$, were also included in the model. The models are represented in the following equation.

$$
Y_{i}=\beta_{0}+\beta_{1} P_{i}+\beta_{2} R_{i}+\beta_{3}\left(P_{i} \times R_{i}\right)+\Sigma_{K=4}^{s} \beta_{\mathrm{k}} X_{i}+\epsilon_{i}
$$

\section{RESULTS}

Overall, 29 participants completed baseline interviews, and 21 participants completed 3-month follow-up interviews. Participation rates were similar at the intervention and control sites. Table 1 shows the baseline demographics of participants who completed both interviews. Participants at the control site were more likely to be male subjects and older than participants at the intervention site. Income was low at both sites, although lower at the intervention site. Participant demographics at the control and intervention sites were similar to the general population in those neighbourhoods. According to census tract data, 97\% of people in both neighbourhoods were African American and the median income was $\$ 15417$ and $\$ 17743$ in the intervention and control neighbourhoods, respectively. ${ }^{33}$ Study participants had higher rates of high school graduation compared with the general neighbourhood population, which was $36 \%$ and $30 \%$ at the intervention and control sites, respectively.

There was a significant amount of vacant land (abandoned homes or vacant lots) at both the intervention and control sites. At the intervention site, $33.5 \%$ of land parcels were vacant, while at the control site, $17.2 \%$ of land parcels were vacant (figure 2 ).

The vacant lot cluster selected for the greening intervention consisted of two separate abandoned, vacant lots. The first vacant lot at the greening site was 1721 square feet and was

Table 1 Demographic characteristics at baseline

\begin{tabular}{|c|c|c|}
\hline & Intervention site $(n=10)$ & Control site $(n=11)$ \\
\hline \multicolumn{3}{|l|}{ Gender } \\
\hline Male (\%) & $50.0 \%$ & $81.8 \%$ \\
\hline Age (year, mean, range) & $38.7(21-57)$ & $51.7(33-65)$ \\
\hline \multicolumn{3}{|l|}{ Race } \\
\hline Black (\%) & $100.0 \% *$ & $100.0 \%$ \\
\hline \multicolumn{3}{|l|}{ Marital status (\%) } \\
\hline Never married & $80.0 \%$ & $27.3 \%$ \\
\hline Married & - & $27.3 \%$ \\
\hline Divorced & $10.0 \%$ & $27.3 \%$ \\
\hline Widowed & $10.0 \%$ & - \\
\hline Separated & - & $18.1 \%$ \\
\hline \multicolumn{3}{|l|}{ Highest education (\%) } \\
\hline Grades $9-12$, no diploma & $20.0 \%$ & $36.4 \%$ \\
\hline HS diploma or GED & $50.0 \%$ & $27.3 \%$ \\
\hline College $1-3$ years, technical & $20.0 \%$ & $27.3 \%$ \\
\hline Bachelors degree & $10.0 \%$ & $9.0 \%$ \\
\hline \multicolumn{3}{|l|}{ Income (annual) (\%) } \\
\hline$<\$ 15000$ & $60.0 \%$ & $27.3 \%$ \\
\hline$\$ 15000-\$ 25000$ & $20.0 \%$ & $9.1 \%$ \\
\hline$\$ 25000-35000$ & $10.0 \%$ & $9.1 \%$ \\
\hline$\$ 35000-45000$ & - & $9.1 \%$ \\
\hline$>\$ 45000$ & - & $18.1 \%$ \\
\hline Refused & $10.0 \%$ & $27.3 \%$ \\
\hline
\end{tabular}

${ }^{*} \mathrm{n}=9$ (1 participant refused) HS; High School, GED; General Education Diploma. located in the middle of the street block between two occupied homes. The vegetation was somewhat overgrown at the start of the study and a car was regularly parked on this vacant lot. The other vacant lot at the greening site was 3484 square feet and was located on the corner of the same street. There was a significant amount of vegetation overgrowth on portions of this vacant lot prior to greening, as well as many pieces of small trash. The control vacant lot cluster also consisted of two separate abandoned, vacant lots. The first vacant lot at the control site was 902 square feet and was located near the end of a street block between two occupied homes. There was significant overgrowth during the course of the study, as well as a pile of trash near the back of the lot with large pieces of wood and metal. The other vacant lot at the control site was 2431 square feet and was located on the corner of a nearby street. This lot appeared to have served some prior purpose, such as a community garden, but had clearly been abandoned and was not currently being maintained. The two sites were separated by over a mile to ensure minimal spill-over effect.

\section{Police reported crime}

In a half-mile buffer around the vacant lot sites, unadjusted difference-in-differences estimates showed reductions for total crime (table 2). At the intervention site, there were 209.0 crimes reported during the 3.5 months prior to greening, and 266.0 crimes reported during the 3.5 months after greening. At the control site, there were 460.0 crimes reported during the 3.5 months prior to greening, and 521.0 crimes reported during the 3.5 months after greening. The net difference-in-differences estimate was -4.0

Aggravated assault with and without a gun, theft, and disorderly conduct were reduced by larger amounts around the intervention site compared with the control site after greening Conversely, robbery with and without a gun, vandalism, narcotics use and distribution, and burglary were increased around the intervention site compared with the control.

In a half-mile buffer around the vacant lot sites, the proportion of all crimes across sites taking place at the intervention site before greening and after greening was $31.2 \%$ and $33.8 \%$, respectively. A $\chi^{2}$ test of this difference was not significant.

\section{Perceptions of disorder}

Prior to the greening intervention, the average disorder scores were 41.8 at the intervention site and 35.9 at the control site. After the greening intervention, the average disorder scores increased to 42.1 and 39.1 at the intervention and the control sites, respectively. The unadjusted difference-in-differences estimate was -2.2 , indicating a net reduction in perceptions of disorder at the intervention site compared with the control site. The regression-adjusted difference-in-differences estimate for total perceived disorder was not significant.

However, participants at the intervention site reported improved perception of safety after greening compared with participants at the control site. Both the unadjusted and regression-adjusted difference-in-differences estimates for perceived neighbourhood safety, one component of the disorder scale, were highly significant $(p<0.01)$. Results were similarly significant with an adjusted ordinal logit model.

\section{DISCUSSION}

The primary aim of this study was to gather preliminary evidence for the impact of greening on police reported crime and perceptions of safety and disorder. Results indicated a non- 
Figure 2 Map showing vacant land status (occupied, vacant lot or abandoned home) at intervention and control sites.

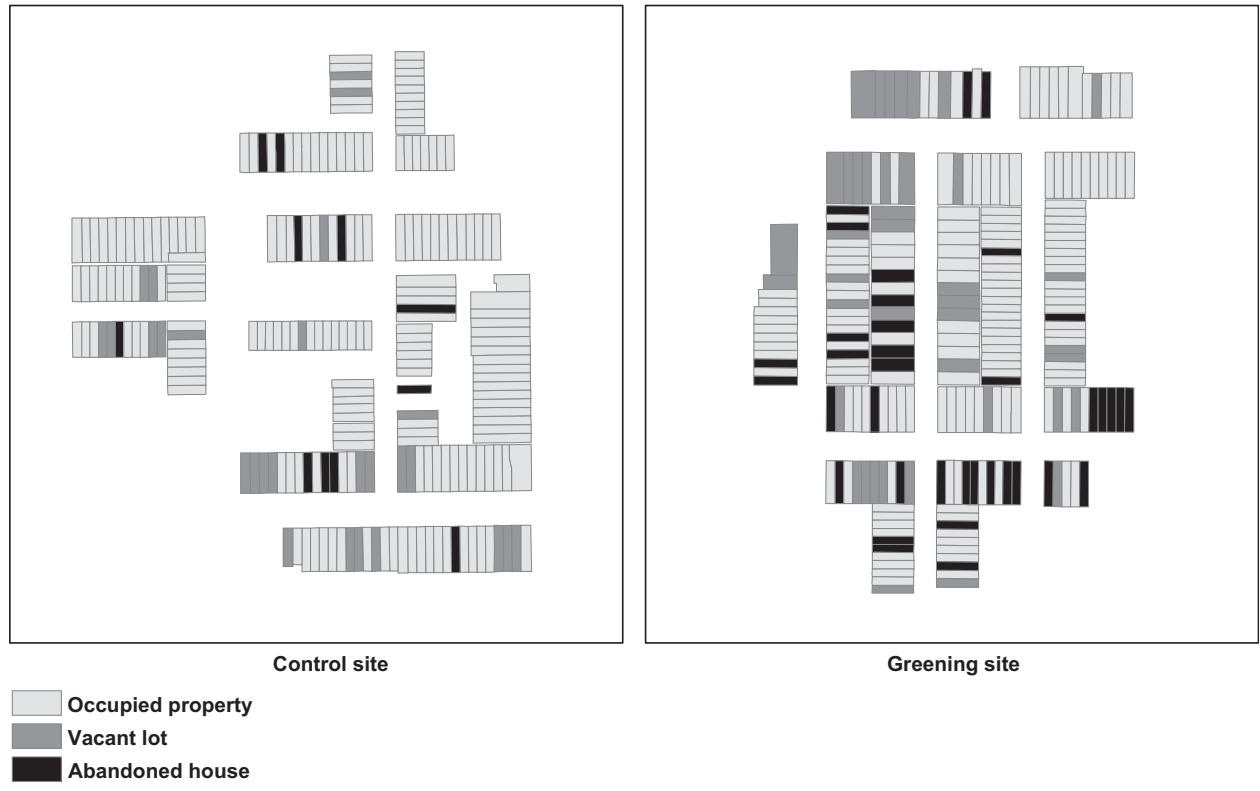

significant net reduction in total crime and aggravated assaults with guns at the greening site compared with the intervention site. While we did not observe a difference in perceptions of disorder, we did observe a significant net increase in residents' perceptions of safety around greened vacant lots compared with non-greened vacant lots.

Vacant lot greening changes the physical environment from one that may promote crime and fear to one that may reduce crime and improve perceptions of safety. Primarily, greening may make it difficult for people to hide illegal guns and conduct other illegal activities such as drug use in or near the space. Prior work has suggested that urban green space may in fact promote fear by decreasing line of site and blocking potential escape routes. $^{34} 35$ Our results suggest the opposite: that well maintained, small scale green space may increase perceptions of safety. This may occur by enhancing neighbourhood pride and encouraging community members to use the space in ways that promote social cohesion. ${ }^{28} 36$ Additionally, green space may reduce stress and mental fatigue associated with living in an urban environment. ${ }^{37}$

The primary limitation of this study was the small sample size of vacant lots. Despite this, findings of the preliminary crime data analysis reported here allow us to generate a hypothesis that total crime and aggravated assaults with guns were affected by greening. However, these results must be

Table 2 Unadjusted difference-in-differences estimates of the impact of vacant lot greening on the numbers of police reported crimes in halfmile buffers around vacant lots

\begin{tabular}{lc}
\hline Outcome & Difference-in-differences estimate \\
\hline Total crime & -4.0 \\
Aggravated assault with gun & -7.0 \\
Aggravated assault without gun & -4.0 \\
Robbery with gun & 4.0 \\
Robbery without gun & 10.0 \\
Theft & -3.0 \\
Disorderly conduct & -15.0 \\
Vandalism & 2.0 \\
Narcotics use and distribution & 4.0 \\
Burglary & 4.0 \\
\hline
\end{tabular}

interpreted with caution as the small number of vacant lot clusters is insufficient to detect statistically significant changes in crime. Furthermore, we were unable to run adjusted regression analysis for the crime changes we did see. The small sample size of vacant lots also resulted in disparate total square footage of the vacant lot space at the intervention and control sites. Similarly, there were differences in the baseline number of crimes at the intervention and control sites. In a larger randomised trial with hundreds of vacant lots, this discrepancy in vacant lot size and numbers of baseline crimes would likely disappear.

The sample size for participant perceptions of safety and disorder was larger, since it was based on the number of participants in the surrounding neighbourhoods and not the number of vacant lot clusters. Therefore, the findings with respect to changes in perceptions of safety can be more robustly interpreted. Still, these findings also warrant further investigation.

Despite the limitations of statistical hypothesis testing, this trial provides evidence for researchers about the feasibility of performing environmental modification studies, including a large randomised controlled trial of vacant lot greening. Although this trial took place in an urban context within the USA, the demonstration of feasibility and improved perceptions of safety after greening has implications for other areas in the USA as well as internationally. For example, previous work from The Netherlands demonstrating that small amounts of disorder, such as graffiti and litter, incite larger amounts of disorder contributed to the theory supporting the current trial. ${ }^{13}$ Similarly, the approach to environmental modification studies described in this manuscript can be adapted by researchers internationally.

In general, researchers may be discouraged from performing environmental modification studies due to logistical and political concerns. Bureaucratic challenges exist in obtaining permissions to perform interventions on neglected public or private land. The PHS, a non-governmental organisation, has a long established relationship with the City of Philadelphia to obtain permission to green vacant lots in a timely manner. We partnered with the PHS who went through their usual municipal channels for approval. This resulted in city owned and 
privately owned vacant lots being approved for greening in a manner that was lawful and timely enough to permit the study.

We recommend developing relationships with local communitybased organisations, municipal governments, community members and others as a means to anticipate and overcome challenges to performing environmental modification studies. For example, community members may voice concern about being randomised to a non-intervention control arm and government officials may be uncomfortable withholding a potentially valuable intervention from some community members. It is essential to carefully explain the importance of randomisation to obtaining the highest level of evidence, and thus the ability to make evidence-based policy recommendations. Although we did not have the resources to do so, we recommend securing funding to also eventually apply the intervention to the control group (essentially creating 'wait-list' controls in a stepped wedge randomised trial design). ${ }^{38}$

Several questions are raised by this study which will need to be addressed in future research. First, how close does one have to live to a greened vacant lot to experience the potential crime and safety benefit? We interviewed people in a fairly small area around the vacant lot sites, but it is possible that the positive effects are experienced farther away. Second, what is the longitudinal impact of vacant lot greening? We demonstrated a benefit of perceived safety 3 months after greening, but it is important to know if this benefit does or does not persist 1 year after greening. Finally, what are the exact mechanisms through which vacant lot greening impacts crime and safety? Further work, both detailed ethnographic fieldwork and time-lapse photography, is needed to elucidate these pathways. ${ }^{39}$

\section{CONCLUSIONS}

Few environmental design interventions have been tested in randomised controlled trials despite the nascent recognition that structural, place-based approaches and modifications to the physical environment may aid in the prevention of crime and enhance health and safety. ${ }^{9}{ }^{40}$ Vacant land is a prime example of a feature of the physical environment that may impact safety and health, and vacant lot greening may be a method to address these concerns. Large randomised controlled trials are now needed to confirm the causal hypotheses raised here. Based on the findings of this smaller trial, these larger randomised trials will likely require hundreds of vacant lots in multiple study arms (greening intervention, trash pickup only and control) to have sufficient statistical power and detect meaningful effect sizes. Such trials would, however, tread new scientific ground and could prove valuable to urban planners, policymakers and public health practitioners, as well as to urban communities currently suffering high rates of crime, violence, fear and attendant decrements in health.

\section{What is already known on the subject}

- Vacant lots are a significant problem in many US cities.

- Vacant lots are often filled with unwanted overgrown vegetation and trash. This makes them attractive places to hide illegal guns and conduct illegal activities such as drug sales and drug use and prostitution.

- A prior quasi-experimental study showed vacant lot greening was associated with reductions in violent crime.

\section{What this study adds}

This is the first randomised control trial of vacant lot greening.

- This study provides preliminary evidence that vacant lot greening may reduce violent crime and increase perceptions of safety.

- This study is a model for future community-based randomised trials of vacant lot greening and other environmental modifications.

Acknowledgements We would like to thank our wonderful community-based interviewers, Denise Heard and Keith Gant.

Contributors ECG led the design of the study, acquisition of data, and analysis and interpretation of data. ECG also led the drafting of the article and approved the final version of the paper. CB conceived of and helped design the study, and also helped with data analysis and interpretation. CCC contributed to the design of the study, as well as analysis and interpretation of data. CB and CCC helped revise the paper critically for important intellectual content and approved the final version of the paper

Funding This work was supported by a grant from the Robert Wood Johnson Health and Society Scholars Educational Fund (no grant number). The funders played no role in study design, data collection or data analysis

\section{Competing interests None.}

Ethics approval Ethics approval was provided by the University of Pennsylvania Institutional Review Board.

Provenance and peer review Not commissioned; externally peer reviewed.

Data sharing statement We are currently analysing data from the qualitative interview and walking interview of this study.

\section{REFERENCES}

1. History of violence as a public health issue Center for Disease Control and Prevention 2009. http://www.cdc.gov/violenceprevention/pdf/history violence-a.pdf laccessed 19 Jun 2011).

2. Sampson RJ. The neighborhood context of well-being. Perspect Biol Med 2003;46 (3 Suppl):S53-64.

3. Richmond TS, Lemaire J. Years of life lost because of gunshot injury to the brain and spinal cord. Am J Phys Med Rehab 2008;87:609-15; quiz 615-18.

4. Zatzick DF, Jurkovich GJ, Gentilello L, et al. Posttraumatic stress, problem drinking, and functional outcomes after injury. Arch Surg-Chicago 2002;137:200-5.

5. Kilpatrick DG, Acierno R. Mental health needs of crime victims: epidemiology and outcomes. J Trauma Stress 2003;16:119-32.

6. Braga AA, Bond BJ. Policing crime and disorder hot spots: a randomized controlled trial. Criminology 2008;46:577-607.

7. Mair JS, Mair M. Violence prevention and control through environmental modifications. Annu Rev Publ Health 2003;24:209-25.

8. Frieden TR. A framework for public health action: the health impact pyramid. Am J Public Health 2010;100:590-5.

9. Yen IH, Syme SL. The social environment and health: a discussion of the epidemiologic literature. Annu Rev Publ Health 1999;20:287-308.

10. Baker SR, Mcclatchey KD. Carcinoma of the nasopharynx in childhood. Otolaryngo Head Neck Surg 1981;89:555-9.

11. Skogan W. Disorder and Decline: Crime and the Spiral of Decay in American Cities. Berkeley: University of California Press, 1990

12. Wei E, Hipwell A, Pardini D, et al. Block observations of neighbourhood physical disorder are associated with neighbourhood crime, firearm injuries and deaths, and teen births. J Epidemiol Community Health 2005;59:904-8.

13. Keizer K, Lindenberg S, Steg L. The spreading of disorder. Science 2008;322:1681-5

14. Spelman W. Abandoned buildings - magnets for crime. J Crim Just 1993;21:481-95

15. Cohen DA, Mason K, Bedimo A, et al. Neighborhood physical conditions and health. Am J Public Health 2003;93:467-71.

16. Ross CE, Mirowsky J. Disorder and decay-The concept and measurement of perceived neighborhood disorder. Urban Aff Rev 1999:34:412-32.

17. Ross CE, Jang SJ. Neighborhood disorder, fear, and mistrust: the buffering role of social ties with neighbors. Am J Community Psychol 2000;28:401-20.

18. Lagrange RL, Ferraro KF, Supancic M. Perceived risk and fear of crime-role of social and physical incivilities. J Res Crime Deling 1992;29:311-34.

19. Vacant Properties - the True Cost to Communities. Washington DC: National Vacan Properties Campaign, 2005.

20. Accordino J, Johnson GT. Addressing the vacant and abandoned property problem J Urban Aff 2000;22:301-15.

21. Vacant Land Management in Philadelphia. Philadelphia: Econsult Corporation, Penn Institute for Urban Research, May 8 Consulting, 2010. 
22. Pagano MA, Bowman A0. Vacant Land in Cities: An Urban Resource, Washington DC: The Brookings Institution, 2000.

23. Brownlow A. An archaeology of fear and environmental change in Philadelphia. Geoforum 2006;37:227-45.

24. Branas CC, Cheney RA, Macdonald JM, et al. A difference-in-differences analysis of health, safety, and greening vacant urban space. Am J Epidemiol 2011:174:1-11.

25. Furr-Holden CD, Lee MH, Milam AJ, et al. The growth of neighborhood disorder and marijuana use among urban adolescents: a case for policy and environmental interventions. J Stud Alcohol Drugs 2011:72:371-9.

26. Cohen DA, Inagami S, Finch B. The built environment and collective efficacy. Health Place 2008;14:198-208.

27. Sampson RJ, Raudenbush SW, Earls F. Neighborhoods and violent crime: a multilevel study of collective efficacy. Science 1997;277:918-24.

28. Kuo FE, Sullivan WC, Coley RL, et al. Fertile ground for community: Inner-city neighborhood common spaces. Am J Community Psychol 1998;26:823-51.

29. Jacobs J. The Death and Life of Great American Cities. New York: Random House, 1961

30. The Pennsylvania Horticulture Society Vacant Land Management. http://www. pennsylvaniahorticulturalsociety.org/phlgreen/current-vacantland.html (accessed 20 Feb 2012)
31. Harris PA, Taylor $R$, Thielke $R$, et al. Research electronic data capture (REDCap)-A metadata-driven methodology and workflow process for providing translational research informatics support. J Biomed Inform 2009;42:377-81.

32. Meyer BD. Natural and quasi-experiments in economics. J Bus Econ Stat 1995;13:151-61

33. United States Census Data. 2000. http://www.cml.upenn.edu/nis/ laccessed 18 Apr 2012).

34. Nasar JL, Fisher B, Grannis M. Proximate physical cues to fear of crime. Landscape Urban Plan 1993:26:161-78.

35. Nasar JL, Jones KM. Landscapes of fear and stress. Environ Behav 1997;29:291-323

36. Sullivan WC, Kuo FE, DePooter SF. The fruit of urban nature - vital neighborhood spaces. Environ Behav 2004;36:678-700.

37. Kuo FE, Sullivan WC. Aggression and violence in the inner city-effects of environment via mental fatigue. Environ Behav 2001:33:543-71.

38. Brown CA, Lilford RJ. The stepped wedge trial design: a systematic review. BMC Med Res Methodol 2006;6:54.

39. Whyte W. The Social Life of Small Urban Spaces. New York: Project for Public Spaces, 1980.

40. Cozens P. Public health and the potential benefits of crime prevention through environmental design. N S W Public Health Bull 2007:18:232-7.

\section{Coalition for gun control}

Based on government documents obtained by the Coalition for Gun Control, the Toronto Star revealed that ending the long-gun registry in Canada represented a far smaller saving than the government had predicted. It also exposed a loophole related to when guns are purchased. Editor's comment: I view the loss of the registry as shameful and I am pleased that my province, Quebec, continues to resist and is determined to proceed on its own.

\section{Florida gun licence backlog grows}

The number of people seeking concealed-weapons licences in Florida skyrocketed following the recent shootings in the USA. One result is having to wait longer than 90 days for a licence. Ironically, and unfortunately, the delay is not due to background checks which are usually accomplished in $72 \mathrm{~h}$. Thus, it is reassuring to know that it may take longer to process applications when background checks show criminal cases with pending dispositions. Editor's comment: It is hard to understand the growing demand and only slightly reassuring to later learn that it is mostly households adding to existing armouries. 